\title{
Does Job Stability Mediate the Relationship Between Intimate Partner Violence and Mental Health Among Low-Income Women?
}

\author{
Adrienne E. Adams and Deborah Bybee \\ Michigan State University
}

\author{
Richard M. Tolman \\ University of Michigan
}

\author{
Cris M. Sullivan and Angie C. Kennedy \\ Michigan State University
}

\begin{abstract}
Intimate partner violence (IPV) has detrimental consequences for women's mental health. To effectively intervene, it is essential to understand the process through which IPV influences women's mental health. The current study used data from 5 waves of the Women's Employment Study, a prospective study of single mothers receiving Temporary Assistance for Needy Families (TANF), to empirically investigate the extent to which job stability mediates the relationship between IPV and adverse mental health outcomes. The findings indicate that IPV significantly negatively affects women's job stability and mental health. Further, job stability is at least partly responsible for the damaging mental health consequences of abuse, and the effects can last up to 3 years after the IPV ends. This study demonstrates the need for interventions that effectively address barriers to employment as a means of enhancing the mental health of low-income women with abusive partners.
\end{abstract}

I ntimate partner violence (IPV) is a major social problem and public health concern. Each year in the United States, an estimated 4.5 million acts of physical violence are committed against women at the hands of an intimate partner (Tjaden \& Thoennes, 2000). Living with violence has significant implications for women's mental health, including PTSD, anxiety, depression, lowered self-esteem, suicidality, and substance abuse (Carlson, McNutt, Choi, \& Rose, 2002; Coker et al., 2002; Pico-Alfonso et al., 2006; Zlotnick, Johnson, \& Kohn, 2006). Although numerous disorders are associated with IPV, depression and anxiety are among the most common (Golding, 1999; Shear, Cloitre, Pine, \& Ross, 2005).

IPV can be experienced by any woman, but rates have been found to be particularly high among low-income women. Studies show that rates of current or recent violence among women receiving welfare range from $10 \%$ to $77 \%$, and lifetime rates of violence range from $22 \%$ to $83 \%$ (Tjaden \& Thoennes, 2000; Tolman \& Raphael, 2000). Women living in poverty often confront tremendous amounts of stress in their everyday lives that

Funding for the Women's Employment Study was provided by the Charles Stewart Mott Foundation, the Joyce Foundation, and the John D. and Catherine T. MacArthur Foundation and by Grant R24MH51363 from the National Institute of Mental Health.

Correspondence concerning this article should be addressed to Adrienne E. Adams, Michigan State University, 139B Psychology Building, East Lansing, Michigan 48912. Electronic mail may be sent to adamsadr@msu.edu. can affect their mental health (Goodman, Smyth, Borget, \& Singer, 2009), including elevated prevalence of depression and depressive symptoms (Lennon, Blome, \& English, 2002). Thus, the added experience of IPV only exacerbates already stressful conditions, further threatening women's psychological health (Goodman et al., 2009).

To develop effective interventions to address the psychological impact of IPV, it is essential to understand the process through which IPV influences women's mental health. IPV has been linked to depression and anxiety through its impact on social support (Beeble, Bybee, Sullivan, \& Adams, 2009), selfesteem (Williams \& Mickelson, 2004), feelings of powerlessness, hopelessness, and loss of control (Bargai, Ben-Shakhar, \& Shalev, 2007; Campbell, Sullivan, \& Davidson, 1995), and coping responses (Calvete, Corral, \& Estevez, 2008). One factor that has not been considered is job instability. Sustaining employment can be a challenge for women with abusive partners. Abusive men often forbid, discourage, or directly prevent their partners from working (Adams, Sullivan, Bybee, \& Greeson, 2008; Alexander, 2011; Riger, Ahrens, \& Blickenstaff, 2001). Batterers' interference with employment has been shown to have a wide range of negative consequences, and for many women, the ultimate employment-related consequence is job loss (Romero, Chavkin, Wise, \& Smith, 2003; Swanberg \& Logan, 2005; Tolman \& Raphael, 2000; Wettersten et al., 2004). In addition to job loss, numerous studies have documented a significant reduction in the amount of time lowincome women with violent partners spend on the job 
compared to other women (Riger, Staggs, \& Schewe, 2004; Staggs \& Riger, 2005; Tolman \& Wang, 2005).

Studies conducted with representative samples of women, low-income women, and low-income women with violent partners have all suggested that employment can have beneficial psychological effects for women to the extent that it fulfills a need for social support, financial resources, a sense of purpose, or a sense of control over one's life (Blustein, 2008; Brush, 2000; Gyamfi, Brooks-Gunn, \& Jackson, 2001; Raver, 2003). When employment is disrupted, women not only lose any positive benefits derived on the job, but they also often experience financial stress that can further erode their mental health (McCallum, Arnold, \& Bolland, 2002; Samuels-Dennis, 2006; Turner, 2007). Taken together, the extant research suggests that employment may be a key point of intervention for improving the mental health of survivors of abuse. Thus, the purpose of the current study was to investigate the extent to which job stability mediates the relationship between IPV and adverse mental health symptoms in low-income women.

\section{Exploring the Relationship of IPV, Employment, and Mental Health}

Previous studies on the intersections among IPV, employment, and mental health have approached the issue from a healthy worker perspective; that is, researchers have focused on understanding mental health as a barrier to sustained employment for survivors of abuse (Chandler, Meisel, Jordan, Rienzi, \& Goodwin, 2005; Corcoran, Danziger, \& Tolman, 2004; Crowne et al., 2011; Helfrich, Fujiura, \& Rutkowski-Kmitta, 2008; Mascaro, Arnett, Santana, \& Kaslow, 2007). In reality, the association between women's employment and mental health is likely bidirectional (Gupta \& Huston, 2009). In other words, while mental health problems can be a significant barrier to employment, there is also evidence suggesting that employment may play an important role in influencing the mental health of survivors. For example, studies show that work can serve as an escape from violence and can be viewed as an important avenue toward economic independence from an abuser (Brush, 2000; Wettersten et al., 2004).

The work-benefits framework suggests that employment may have beneficial mental health effects to the extent that it provides women with greater opportunities for financial resources, power and a sense of control over their lives, social support and connectedness, as well as self-esteem and a social identity (Ali \& Avison, 1997; Blustein, 2008; Davies \& McAlpine, 1998; Gupta \& Huston, 2009; Repetti, Matthews, \& Waldron, 1989; Rothman, Hathaway, Stidsen, \& deVries, 2007). Numerous studies have demonstrated a positive relationship between lowincome women's employment and psychological well-being. For instance, Danziger, Carlson, and Henly (2001) found that, controlling for job quality, former welfare recipients who found employment after leaving welfare were at lowered risk for depression and had higher life satisfaction compared to those who were unemployed. Similarly, Gyamfi et al. (2001) found that low-income single Black mothers who were employed had fewer symptoms of depression than their unemployed counterparts, even though both groups of women experienced high levels of financial strain. Further, financial strain was related to depression for unemployed single mothers, but not for mothers who were working, suggesting that the financial strain experienced by employed mothers was not influencing their mental health. The authors concluded that employed mothers might have derived a greater sense of purpose from their employment, reducing the effect that financial strain might have had on their psychological health.

Just as employment can have positive mental health effects, the stress process model draws attention to the negative psychological consequences of job instability (Pearlin, 1989). From this perspective, undesirable job change or loss is a negative life event that can trigger a chain of stressful conditions and result in adverse mental health outcomes (Price, Choi, \& Vinokur, 2002; Turner, 2007). Studies with economically diverse samples have shown that the stress of unstable employment has negative mental health consequences for women. For example, Thomas, Benzeval, and Stansfeld (2007) reported that women who moved from employment to unemployment were at increased risk for psychological distress, and the relationship between employment transitions and mental health was partially explained by their financial circumstances. The financial stress resulting from the loss of income has been studied as a key mediator in the stress process model (Price et al., 2002; Turner, 2007). When applied to low-income women, this framework suggests that job instability contributes to chronic financial strain, which is often a precursor to material hardships such as food insufficiency, housing instability, a lack of transportation, and inadequate medical care (McCallum et al., 2002; SamuelsDennis, 2006). Studies show that under conditions of financial strain and material deprivation, low-income women's risk for mental health problems increases (Brown \& Moran, 1997; Jackson, Brooks-Gunn, Huang, \& Glassman, 2000; Lynch, Kaplan, \& Shema, 1997; Samuels-Dennis, 2006; Turner, 2007). Taken together, the work-benefits and stress process models suggest that when an abusive intimate partner threatens a woman's employment, he is potentially jeopardizing the financial resources, supports, and sense of control that employment provides, and, as a consequence, mental health can suffer.

\section{The Current Study}

Building on previous research and drawing from the workbenefits framework and stress process model to connect employment to women's mental health, the current study advances prior research by testing the mediating role of job stability in explaining the effects of IPV on the mental health of a longitudinal sample of low-income women. As shown in Figure 1, women were categorized into groups based on the timing of their IPV experiences over the course of the study to allow for examination of the immediate and longer term mental health effects of abuse. Research indicates that the psychological effects of IPV depend to some extent on the severity and recency of the violence. Several studies have shown that more severe forms of violence are associated with increased mental health problems (Coker et al., 2002; Dienemann et al., 2000; McCauley, Kern, Kolodner, Derogatis, \& Bass, 1998; SatoDiLorenzo \& Sharps, 2007). Some studies suggest that IPV has an immediate impact on women's mental health, but once the violence ends, symptoms subside (Anderson, Saunders, 


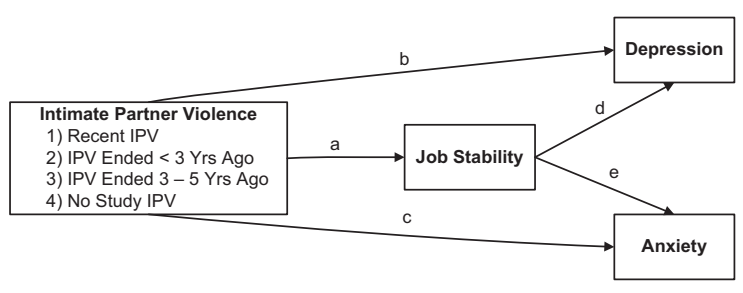

$\bullet$ Waves 1-5 $\longrightarrow$

Figure 1. Conceptual model.

Yoshihama, Bybee, \& Sullivan, 2003; Beeble, Bybee, \& Sullivan, 2010; Campbell \& Soeken, 1999; Campbell et al., 1995; Tolman \& Rosen, 2001), whereas other research has demonstrated lasting effects of abuse on women's mental health (Bonomi, Anderson, Rivara, \& Thompson, 2007; von Eye \& Bogat, 2006).

We hypothesized that IPV would be inversely related to job stability (path a), positively related to depression (path b), and positively related to anxiety (path c), such that the effects would be strongest for women experiencing the most recent abuse and diminish over time. We also expected job stability to be inversely related to depression (path d) and anxiety (path e). Further, we hypothesized that job stability would partially mediate the relationships between IPV and depression, as well as IPV and anxiety.

\section{Method}

\section{Participants}

This study used data from five waves of the Women's Employment Study, a longitudinal study of single mothers receiving Temporary Assistance for Needy Families (TANF) in February of 1997. The initial sample was drawn from a list of all the single mothers in one urban county in Michigan. Stratified random sampling was used to proportionally select cases by zip code, race (non-Hispanic, White, or African American), and age (18-54). Of the 874 women who met the selection criterion, 753 (86\% response rate) participated in the Wave 1 interview in the fall of 1997 . Wave 2 and Wave 3 interviews took place at 1-year intervals and resulted in a $92 \%$ and $91 \%$ response rate, respectively. Two years after Wave 3, 91\% of the remaining sample participated in the Wave 4 interview, and then 2 years later, $93 \%$ of those women participated in the Wave 5 interview. A total of 536 women participated in all five waves of the study; the attrition rate was $29 \%$. Of the women who completed all five interviews, 33 who were unemployed because of disability were excluded from this study, leaving a final sample of 503 women.

\section{Procedure and Measures}

Face-to-face structured interviews lasting approximately $1 \mathrm{hr}$ were conducted by a group of specially trained interviewers beginning in the fall of 1997 and ending in early 2004. Prior to the start of the interview, each participant was informed of her rights and of the researchers' responsibilities and was given a copy of the consent form. The following measures from the interview were used in this study.

Intimate partner violence. A six-item severe violence measure from the Conflict Tactics Scale (Straus, 1979) was used to assess IPV. At each interview, women were asked whether an intimate partner had (a) "hit you with a fist," (b) "hit you with an object that could hurt you," (c) "beaten you," (d) "choked you," (e) "threatened to or used a weapon," and (f) "forced you into any sexual activity against your will." At Wave 1, women were asked whether they had ever experienced each type of violence in an intimate relationship and, if so, if it had happened in the past 12 months. At Waves 2-5, women were asked whether they had experienced each type of violence since the previous interview. With this information, women were categorized into four groups based on the timing of their IPV experiences. First, the $63(13 \%)$ women who reported experiencing IPV during Wave 5 became the Recent IPV group. The second group consisted of 67 $(13 \%)$ women who experienced IPV at Wave 3 or 4 , but not at Wave 5; as their most recent IPV experience ended up to 3 years prior to Wave 5, these women became the IPV Ended Within Last 3 Years group. The third group included 61 $(12 \%)$ women who had experienced IPV at Wave 1 or 2 but not at Wave 3, 4, or 5. As their most recent IPV ended 3 to 5 years prior to the time frame assessed at Wave 5, these women were categorized as IPV Ended 3-5 Years Ago. The remaining 312 women $(62 \%)$ had not experienced IPV at any point during the five waves of the study. At the Wave 1 interview, some of these women reported past IPV. However, the timing of this experience could not be determined, and for some women, it may have been as long as 40 years earlier. Given the study aim of attending to the persistence of IPV's mental health effects, these women were combined with those reporting no lifetime IPV to form a No Study IPV group, indicating that they had not experienced severe physical abuse during the years of the study. To summarize, women were grouped into four categories: (a) Recent IPV, (b) IPV Ended Within Last 3 Years, (c) IPV Ended 3-5 Years Ago, and (d) No Study IPV. For analyses, three dummy variables were created with No Study IPV used as the reference group. Cronbach's alpha was as follows at each wave: Wave 1, $\alpha=.86$; Wave 2, $\alpha=.83$; Wave $3, \alpha=.81$; Wave $4, \alpha=.83$; Wave $5, \alpha=.84$.

Job stability. At Wave 5, women were asked "How many times have you changed your main job, that is, changed employers since [the last interview]?" On average, the number of months between Wave 4 and Wave 5 interviews was 24.14, with a standard deviation of 1.46. The maximum number of job changes women reported was 7 , while the minimum was 0 . Participants also reported whether they had worked for pay in each month since the last interview. The job stability variable was computed as the number of months worked since the last interview divided by the number of job changes (plus a constant of 1 to remove the 0 value from the equation). Hence, job stability was operationalized as the average number of months at any one job since the last interview. Scores ranged from 0 to $29($ mean $=12.88 ; S D=9.35)$. 
Mental health. The WHO-CIDI-SF (Kessler, Andrews, Mroczek, Ustun, \& Wittchen, 1998), an instrument used to diagnose major depression and generalized anxiety disorder, was used to measure depression and anxiety at Wave 5. To maximize variability in the outcomes, rather than dichotomous diagnosis measures, continuous symptom count variables were computed. For depression, participants were first asked whether they had felt sad, blue, or depressed or lost interest in most things for at least most of the day, almost every day of the week, for at least 2 weeks in a row at any point during the past 12 months. Women who said "no" were scored as having " 0 " symptoms of major depression. Women who reported "yes" were asked to report whether they had experienced any of the following during that 2-week period: losing interest, feeling tired, losing or gaining weight, having trouble falling asleep, having trouble concentrating, feeling down on yourself, and having thoughts about suicide. To calculate a score for these participants, the number of symptoms was counted. Scores on the depression variable ranged from 0 to 7 (mean $=1.21$; $S D=2.23$ ). A negative reciprocal transformation was used to reduce skewness and kurtosis. After the transformation was applied, the skewness value was 1.07 , and kurtosis was -.70 . The internal consistency coefficient for the depression scale with this sample was .94 .

Similarly for anxiety, women were first asked whether they had felt worried, tense, or anxious most of the time for a period of 1 month or longer during the past 12 months. Women who said "no" were scored as having "0" symptoms of generalized anxiety disorder. Those who reported "yes" were asked whether they experienced the following during that period: restlessness, feeling keyed up or on edge, irritability, pounding or racing heart, fatigue, difficulty falling asleep, and dizziness or lightheadedness. To calculate a score for these participants, the number of symptoms was counted. Scores on the anxiety variable ranged from 0 to 7 (mean $=1.04 ; S D=2.21$ ). To make the distribution of the anxiety variable suited to normality assumptions, the negative reciprocal transformation was applied, resulting in a skewness value of 1.59 and kurtosis of .54. The anxiety scale yielded an alpha coefficient of .96 .

Control variables. Variables known to be associated with low-income women's mental health and employment (Staggs \& Riger, 2005; Tolman \& Wang, 2005) were controlled for in the analyses: (a) a race binary variable indicating whether the participant was African American, (b) participant's age at the time of the Wave 5 interview, (c) level of education (less than a high school education, completed high school/GED, had some college education, or completed 4 years of college) as of the Wave 5 interview was included, (d) a binary variable indicating whether there were children under the age of 14 in the household, and (e) the percent of years the participant had received public assistance from the age of 18 to the start of the study in 1997.

\section{Analysis}

To focus on the temporal ordering of the constructs in the hypothesized model, path analysis was performed with the structural equation modeling software AMOS version 17.0, and
ML methods were used to estimate model parameters. Of the 536 women who completed all five interviews, 33 who were unemployed because of disability were excluded from this study, leaving a final sample of 503 women. With $<1 \%$ of values missing from the data set, two approaches were used to handle the minimal missing data in this analysis. First, the path analysis was performed using full information maximum likelihood estimation (FIML). The FIML procedure was appropriate because it produces accurate coefficient estimates and model fit indices with up to $25 \%$ missing data (Enders \& Bandalos, 2001). Second, expectation maximization (EM) methods were used to estimate the missing values so that modification indices could be calculated and the bootstrap procedure could be run in Amos with complete data. The estimates produced with the incomplete data set and imputed data were compared to confirm there were no major differences.

Following the recommendation of $\mathrm{Hu}$ and Bentler (1999), three different types of fit indices were applied to evaluate model fit: (a) A nonsignificant chi-squared statistic (CMIN) was used as an indicator of good absolute model fit, (b) root mean square error of approximation (RMSEA; Browne \& Cudeck, 1993), with a cut-off value of $<.06$, was used as an indicator of fit between the hypothesized model and the true population model, correcting for the complexity of the model, and (c) the comparative fit index (CFI; Bentler, 1990), with a value greater than 95 , was used as an indicator of substantial improvement in fit of relative to the null or independence model. Local model fit was also assessed by examining modification indices. To reduce model complexity, nonsignificant paths were constrained to zero. To ensure that these constraints did not significantly affect model fit, trimmed models were compared with the fully estimated model using likelihood ratio chi-squared tests (LR $\chi^{2}$ )

Once a model that adequately fit the data had been established, the final path model was used to test and interpret the hypothesized direct and indirect effects. Consistent with MacKinnon (2008), to test the primary mediational hypothesis of this study, bootstrapping (bias-corrected, with $95 \%$ confidence intervals) was used to determine the statistical significance of the indirect effects. The bootstrap procedure takes repeated samples from the original sample to compute a given parameter. The distribution of the parameter produced from the repeated sampling is used to estimate the variance in the population, which allows the significance of the parameters to be estimated (MacKinnon, Lockwood, Hoffman, West, \& Sheets, 2002). This procedure is a preferred alternative to other methods for testing mediation because of its ability to yield unbiased estimates and its greater power to detect effects.

\section{Results}

On average, study participants were 36 years old $(S D=7.35)$, just over half of the women were African American $(56 \%), 80 \%$ had children under age 14 in the household, and $75 \%$ were unmarried at the time of the Wave 5 interview. Seventy-two percent had at least a high school education, and the majority were employed (66\%). Participants' average gross household income was $\$ 20,622$ for the year 2002 (range $\$ 1,000$ to $\$ 90,000$ ). When the study began in 1997 , all of the women 
were receiving TANF; in 2003, 32\% were receiving assistance. The majority of the women had experienced severe IPV during their lifetime (62\%); of those women, $29 \%$ were in a severely violent relationship during the first 3 years of the study, and $13 \%$ recently experienced severe IPV (i.e., during the last two waves of the study). The women who were recently abused reported that they had been hit with a fist $(6 \%)$, hit with an object $(6 \%)$, beaten up $(5 \%)$, strangled $(7 \%)$, threatened with a weapon $(5 \%)$, and forced into sexual activity $(2 \%)$.

\section{Path Model}

The model fitting process was informed by a combination of theory and examination of the empirical relationships. Through a systematic process of examining hypothesized associations between variables (see Figure 1) and trimming nonsignificant paths, we arrived at a final path model that showed excellent fit, $\chi^{2}(N=503,27)=23.36, p=.67, \mathrm{RMSEA}=.00,90 \%(\mathrm{CI})$ $=.000-.029, \quad \mathrm{CFI}=1.0$. Several significant relationships between the control variables and primary variables of interest remained in the final model. Education was inversely related to Recent IPV $(B=-0.03, p<.01)$ and positively associated with job stability $(B=1.60, p<.001)$. Age was significantly positively related to depression $(B=0.01, p<.01)$, inversely associated with Recent IPV $(B=-0.29, p<.01)$ and IPV Ended Within Last 3 Years $(B=-0.27, p<.01)$. Finally, having children under age 14 in the household was significantly inversely related to job stability $(B=-2.19, p<.05)$. The final path model accounted for $6 \%$ of the variance in job stability, $4 \%$ of the variance in anxiety, and $6 \%$ of the variance depression.

\section{Direct Effects}

To examine the direct effects of IPV on job stability, depression, and anxiety, the paths from job stability to the mental health outcome variables were set to zero (see Figure 2). As hypothesized, after controlling for the effects of education, age,

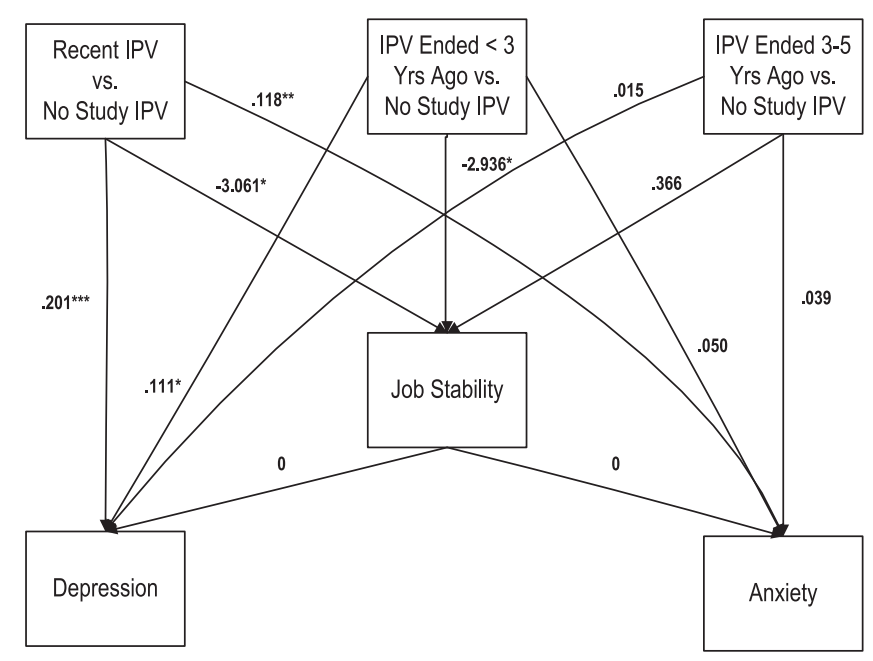

Figure 2. Direct effects path model. *Significant at .05. **Significant at $.01 .{ }^{* * *}$ Significant at .001 . and having children under age 14, IPV was significantly related to women's job stability (path a). Specifically, Recent IPV and IPV Ended Within Last 3 Years were significantly inversely related to job stability $(B=-3.06, p<.05 ; B=-2.94, p<.05$, respectively). This means that, compared with women who had not experienced IPV during the study, women who recently experienced IPV worked 3.06 fewer months at any one job, and women whose IPV ended within the last 3 years worked 2.9 months less at any one job, after accounting for the effects of education, age, and having children under age 14. IPV Ended 3-5 Years Ago was not significantly related to job stability $(B=.37, p=.774)$.

We also hypothesized significant direct effects of IPV on women's depression (path b) and anxiety (path c). As expected, controlling for the effects of education, age, and having children under age 14, Recent IPV and IPV Ended Within Last 3 Years were significantly positively related to depression ( $B=0.20, p<.001 ; B=0.11, p<.05$, respectively), and Recent IPV was significantly positively related to anxiety $(B=0.12$, $p<.01)$. Contrary to our hypothesis, IPV Ended Within Last 3 Years was not significantly directly related to anxiety $(B=0.05, p=.259)$ and IPV Ended 3-5 Years Ago was not significantly directly related to depression or anxiety $(B=0.02$, $p=.758 ; B=0.04, p=.395$, respectively).

\section{Indirect Effects}

The primary aim of this study was to examine job stability as a mediator of the relationship between IPV and low-income women's depression (path d) and anxiety (path e). As hypothesized, after accounting for the effects of education, age, and having children under age 14, Recent IPV and IPV Ended Within Last 3 Years had a significant indirect effect on depression (indirect $B=0.01, p<.01$ and indirect $B=0.01, p<.01$, respectively) and anxiety (indirect $B=0.02, p<.01$ and indirect $B=0.02, p<.01$, respectively) through job stability. Contrary to our hypothesis, the indirect effects for depression and anxiety were not significant for IPV Ended 3-5 Years Ago $(B=-0.002, p=.71 ; B=-0.002, p=.81$, respectively).

To determine whether the significant direct effects were partially or fully mediated by job stability, ${ }^{1}$ a model was estimated with the paths from IPV to the mental health outcomes set to zero and the remaining paths allowed to vary. Comparison with the full model showed that model fit significantly worsened when the IPV-depression paths were set to zero, LR $\chi^{2}(N=503,3)=17.22, p=.001$, but not when the IPV-anxiety paths were set to zero, $\operatorname{LR} \chi^{2}(N=503,3)=5.06, p=.17$ These findings indicate that a significant portion of the overall variance was explained by the direct paths from IPV to depression but not by the direct paths from IPV to anxiety, meaning job stability partially mediated the relationship between IPV and depression and fully mediated the relationship between IPV and anxiety. The full path model is shown in Figure 3, and all indirect effects are provided in Table 1.

\footnotetext{
${ }^{1}$ There must be a significant unconditional direct effect between the independent and dependent variables for an indirect effect to be interpreted as mediation (MacKinnon, 2008).
} 
Table 1. Indirect Effects

\begin{tabular}{|c|c|c|c|c|c|c|c|c|c|}
\hline & \multicolumn{3}{|c|}{ Recent IPV vs. No study IPV } & \multicolumn{3}{|c|}{$\begin{array}{c}\text { Ended }<3 \text { years ago vs. No study } \\
\text { IPV }\end{array}$} & \multicolumn{3}{|c|}{$\begin{array}{c}\text { Ended } 3-5 \text { years ago vs. No study } \\
\text { IPV }\end{array}$} \\
\hline & $B$ & $p$ & Effect type & $B$ & $p$ & Effect type & $B$ & $p$ & Effect type \\
\hline Anxiety & 0.017 & $<.01$ & FM & 0.016 & $<.01$ & $\mathrm{n}$ & -0.002 & .81 & None \\
\hline
\end{tabular}

Effect type: FM, Full mediation; PM, partial mediation; IE, indirect effect.

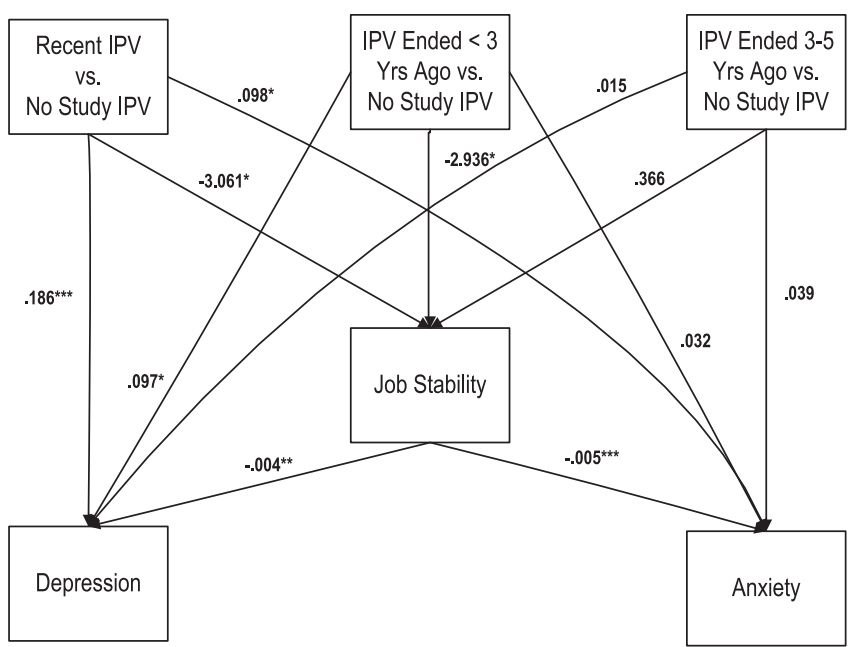

Figure 3. Full path model. *Significant at .05. **Significant at .01. $* * *$ Significant at .001 .

\section{Discussion}

The findings from this study provide further evidence of the damaging consequences of IPV for women's job stability and mental health. First, the results demonstrate that IPV has immediate as well as longer term implications for women's job stability. Our finding that IPV occurring in the past 12 months significantly reduced the amount of time spent at any one job is consistent with several prior studies showing that women who are currently or have recently been in an abusive relationship spend significantly less time in paid employment compared to nonabused women (Crowne et al., 2011; Riger et al., 2004; Staggs \& Riger, 2005; Tolman \& Wang, 2005). Additionally, this study adds to mounting evidence suggesting that past IPV has sustained effects on women's employment stability. We found that IPV had a significant detrimental impact on women's job stability for up to 3 years after the abuse had ended, Lindhorst, Oxford, and Gillmore (2007) showed an effect 4 and 5 years later, and Crowne et al. (2011) reported effects lasting nearly 6 years. The variation in findings across these studies is at least partly because of differences in the employment outcome measured; however, the conclusion is consistent: IPV survivors could struggle to sustain employment for some time after the abuse ends.

Second, our results showed that recency of IPV has a bearing on women's mental health. Women who had experienced severe physical abuse in the past 12 months had significantly higher depression than women who had not experienced such abuse during the past 7 years. While the relationship was not as strong as it was for recent IPV, depression was significantly greater among women for whom the abuse had ended up to 3 years ago compared to women who had not been victimized during the study. Only recent abuse was significantly related to anxiety; that is, women who had experienced severe partner violence in the past 12 months had significantly greater anxiety than women who had not experienced IPV during the study, but women for whom the abuse had ended up to 3 or 3 to 5 years ago did not report significantly higher anxiety than women who had not been victimized during the study. Collectively, these findings suggest that IPV may be most damaging to women's mental health in the short term, but also has some lasting effects in the years following the abuse that subside over time. This is consistent with recent longitudinal studies investigating the long-term psychological effects of IPV (Beeble et al., 2009, 2010).

Our primary aim was to test the mediational role of job stability on the IPV-mental health relationship. Previous research has shown that mental health can serve as a barrier to employment for women (Chandler et al., 2005; Coiro, 2001; Corcoran et al., 2004; Crowne et al., 2011; Danziger et al., 2001; Helfrich et al., 2008; Mascaro et al., 2007; Riger, Ahrens, Blickenstaff, \& Camacho, 1999; Yoshihama, Hammock, \& Horrocks, 2006). This was the first study to consider an economic pathway from IPV to mental health outcomes. As expected, the results established an indirect effect of IPV on mental health through job stability. The effect of IPV on depression was partially explained by decreased job stability when comparing both women who experienced recent IPV and women for whom the abuse had ended up to 3 years ago with women who had not been victimized during the study. The effect of IPV on anxiety was fully explained by lower job instability when comparing women who were recently abused by an intimate partner to women who had not been in an abusive relationship during the 7 years of the study. Although no significant direct relationship was found between IPV that ended up to 3 years ago and anxiety, there was a significant indirect effect through job stability. In other words, compared to women who had not been victimized by an intimate partner during the study, women for whom the physical abuse had ended up to 3 years ago had significantly less stable employment and that job instability led to significantly more anxiety. It is important to note that all of these effects were significant after the control variables-education, age, and having children under age 14-were taken into account. Taken together, these findings suggest that regardless of education, age, and having to provide for children under age 
14, women's mental health is to some extent directly tied to their level of job stability, which can be significantly compromised by an abusive partner at the time the abuse is occurring and for up to 3 years after the abuse ends.

It is necessary to consider these findings in light of the limitations. First, the mental health measures used in this study were derived from an instrument used to diagnose major depression and generalized anxiety disorder. This meant that participants had to meet the criteria of persistent sadness or worry to register a score greater than " 0 ." While disorder-based measurement permits identification of women struggling with the most severe and persistent mental health problems, it may fail to capture more mild symptoms that could also impair functioning and diminish quality of life. Future research on the mental health of IPV survivors should include instruments designed to broadly assess mental health symptom severity across all women in addition to diagnostic measures of mental health disorders. Second, testing of a meditational model requires temporal ordering of the key variables of interest, and this study did have some overlap in measurement. Specifically, IPV was measured across all five waves, job stability was measured during the last two waves, and mental health was assessed for the past 2 weeks of the study. While the overlap is not ideal, the general temporal ordering in measurement does heighten confidence in the mediational findings of the study.

Limitations notwithstanding, this study's central finding that IPV affects women's mental health through job stability has notable implications for research and practice. This study calls for research investigating the economic pathway connecting IPV and mental health outcomes. Studies could focus on examining the mechanisms by which job stability affects mental health in the context of IPV; any number of social, psychological, or economic factors such as social support, sense of control, self-efficacy, income, access to insurance, or financial strain could be driving this relationship. Also, researchers could begin exploring characteristics of employment that are critical to IPV survivors' mental health. Is any job better than no job or are certain conditions necessary for IPV survivors to derive psychological benefits from employment? Additionally, longitudinal research is needed to investigate the dynamic, reciprocal relationship between job stability and mental health for IPV survivors.

Our findings also suggest the need for programs and policies that target employment as a mechanism for improving the mental health of low-income IPV survivors. This applies not only to women who are seeking safety from a current or recent abusive partner, but also to those who are recovering from the residual effects of a past abusive relationship. IPV service providers, including counselors, advocates, and case managers, could help women identify and overcome barriers to employment stability. This may range from job search assistance, to finding child care and transportation resources, to advocating with an employer who is threatening dismissal because of abuse. Further, community-based employment and financial programs that serve low-income women need to be educated about IPV-related safety issues and employment barriers to effectively meet the unique needs of IPV survivors. These types of help and support are increasingly critical in an economy where fewer jobs are available overall, low-income workers are earning less and having to work more, and the financial safety net is weakening. The current economic context necessitates comprehensive community-wide initiatives to safely move lowincome IPV survivors into not just any job, but living wage jobs. Further, funders and policy-makers need to understand that investing in the gainful employment of women is an investment in the health and well-being of individuals, families, and communities.

Keywords: low-income women; intimate partner violence; women's mental health; depression; anxiety; work-benefits framework; job stability

\section{References}

Adams, A. E., Sullivan, C. M., Bybee, D., \& Greeson, M. R. (2008). Development of the scale of economic abuse. Violence Against Women, 14, 563.

Alexander, P. (2011). Childhood maltreatment, intimate partner violence, work interference, and women's employment. Journal of Family Violence, 26, 255-261.

Ali, J., \& Avison, W. R. (1997). Employment transitions and psychological distress: The contrasting experiences of single and married mothers. Journal of Health and Social Behavior, 38, 345-362.

Anderson, D. K., Saunders, D. G., Yoshihama, M., Bybee, D. I., \& Sullivan, C. M. (2003). Long-term trends in depression among women separated from abusive partners. Violence Against Women, 9, 807.

Bargai, N., Ben-Shakhar, G., \& Shalev, A. (2007). Posttraumatic stress disorder and depression in battered women: The mediating role of learned helplessness. Journal of Family Violence, 22, 267-275.

Beeble, M. L., Bybee, D., \& Sullivan, C. M. (2010). The impact of resource constraints on the psychological well being of survivors of IPV over time. Journal of Community Psychology, 38, 943-959.

Beeble, M. L., Bybee, D., Sullivan, C. M., \& Adams, A. E. (2009). Main, mediating, and moderating effects of social support on the well-being of survivors of intimate partner violence across two years. Journal of Consulting and Clinical Psychology, 77, 718-729.

Bentler, P. M. (1990). Fit indexes, lagrange multipliers, constraint changes and incomplete data in structural models. Multivariate Behavioral Research, 25, 163-172.

Blustein, D. L. (2008). The role of work in psychological health and well-being: A conceptual, historical, and public policy perspective. American Psychologist, 63, 228-240.

Bonomi, A., Anderson, M., Rivara, F., \& Thompson, R. (2007). Health outcomes in women with physical and sexual intimate partner violence exposure. Journal of Women's Health, 16, 987-997.

Brown, G., \& Moran, P. (1997). Single mothers, poverty and depression. Psychological Medicine, 27, 21-33.

Browne, M., \& Cudeck, R. (1993). Alternative ways of assessing model fit. In K. Bollen \& J. Long (Eds.), Testing structural equation models (pp. 136-162). Newbury Park, CA: Sage.

Brush, L. D. (2000). Battering, traumatic stress, and welfare-to-work transition. Violence Against Women, 6, 1039-1065.

Calvete, E., Corral, S., \& Estevez, A. (2008). Coping as a mediator and moderator between intimate partner violence and symptoms of anxiety and depression. Violence Against Women, 14, 886.

Campbell, J. C., \& Soeken, K. L. (1999). Women's responses to battering over time: An analysis of change. Journal of Interpersonal Violence, 14, 21-40.

Campbell, R., Sullivan, C., \& Davidson, W. (1995). Women who use domestic violence shelters: Changes in depression over time. Psychology of Women Quarterly, 19, 237-255.

Carlson, B. E., McNutt, L. A., Choi, D. Y., \& Rose, I. M. (2002). Intimate partner abuse and mental health: The role of social support and other protective factors. Violence Against Women, 8, 720-745. 
Chandler, D., Meisel, J., Jordan, P., Rienzi, B. M., \& Goodwin, S. N. (2005). Mental health, employment, and welfare tenure. Journal of Community Psychology, 33, 587.

Coiro, M. J. (2001). Depressive symptoms among women receiving welfare. Women and Health, 32, 1-2.

Coker, A. L., Davis, K. E., Arias, I., Desai, S., Sanderson, M., \& Brandt, H. M. (2002). Physical and mental health effects of intimate partner violence for men and women. American Journal of Preventive Medicine, 23, 260-268.

Corcoran, M., Danziger, S. K., \& Tolman, R. M. (2004). Long term employment of African-American and White welfare recipients and the role of persistent health and mental health problems. Women and Health, 39(4), 21-40.

Crowne, S. S., Juon, H. S., Ensminger, M., Burrell, L., McFarlane, E., \& Duggan, A. (2011). Concurrent and long-term impact of intimate partner violence on employment stability. Journal of Interpersonal Violence, 26, 1282-1304.

Danziger, S. K., Carlson, M. J., \& Henly, J. R. (2001). Post-welfare employment and psychological well-being. Women and Health, 32, 1-2.

Davies, L., \& McAlpine, D. D. (1998). The significance of family, work, and power relations for mothers' mental health. Canadian Journal of Sociology, 23, 369-387.

Dienemann, J., Boyle, E., Baker, D., Resnick, W., Wiederhorn, N., \& Campbell, J. (2000). Intimate partner abuse among women diagnosed with depression. Issues in Mental Health Nursing, 21, 499-513.

Enders, C., \& Bandalos, D. (2001). Relative performance of full information maximum likelihood estimation for missing data in structural equation models. Structural Equation Modeling, 8, 430-457.

Golding, J. M. (1999). Intimate partner violence as a risk factor for mental disorders: A meta-analysis. Journal of Family Violence, 14, 99-132.

Goodman, L. A., Smyth, K. F., Borget, A. M., \& Singer, R. (2009). When crises collide: How intimate partner violence and poverty intersect to shape women's mental health and coping. Trauma, Violence, \& Abuse, 10, 306-329.

Gupta, A. E., \& Huston, A. C. (2009). Depressive symptoms and economic outcomes of low income women: A review of the social causation, social selection, and interactionist hypotheses. Social Issues and Policy Review, 3, 103-140.

Gyamfi, P., Brooks-Gunn, J., \& Jackson, A. P. (2001). Associations between employment and financial and parental stress in low-income single black mothers. Women and Health, 32, 1-2.

Helfrich, C. A., Fujiura, G. T., \& Rutkowski-Kmitta, V. (2008). Mental health disorders and functioning of women in domestic violence shelters. Journal of Interpersonal Violence, 23, 437-453.

Hu, L., \& Bentler, P. M. (1999). Cutoff criteria for fit indexes in covariance structure analysis: Conventional criteria versus new alternatives. Structural Equation Modeling, 6, 1-55.

Jackson, A. P., Brooks-Gunn, J., Huang, C., \& Glassman, M. (2000). Single mothers in low wage jobs: Financial strain, parenting, and preschoolers' outcomes. Child Development, 71, 1409-1423.

Kessler, R. C., Andrews, G., Mroczek, D., Ustun, B., \& Wittchen, H. U. (1998). The World Health Organization Composite International Diagnostic Interview short-form (CIDI-SF). International Journal of Methods in Psychiatric Research, 7(4), 171-185.

Lennon, M. C., Blome, J., \& English, K. (2002). Depression among women on welfare: A review of the literature. Journal of the American Medical Women's Association, 57, 27-32.

Lindhorst, T., Oxford, M., \& Gillmore, M. R. (2007). Longitudinal effects of domestic violence on employment and welfare outcomes. Journal of Interpersonal Violence, 22, 812-828.

Lynch, J. W., Kaplan, G. A., \& Shema, S. J. (1997). Cumulative impact of sustained economic hardship on physical, cognitive, psychological, and social functioning. New England Journal of Medicine, 337, 1889-1895.
MacKinnon, D. P. (2008). Introduction to statistical mediation analysis. New York: Erlbaum Psychiatric Press.

MacKinnon, D. P., Lockwood, C., Hoffman, J. M., West, S. G., \& Sheets, V. (2002). A comparison of methods to test mediation and other intervening variable effects. Psychological Methods, 7, 83-104.

Mascaro, N., Arnett, N. C., Santana, M. C., \& Kaslow, N. J. (2007). Longitudinal relations between employment and depressive symptoms in low-income suicidal African American women. Journal of Clinical Psychology, 63, 541-553.

McCallum, D. M., Arnold, S. E., \& Bolland, J. M. (2002). Low-income African-American women talk about stress. Journal of Social Distress and the Homeless, 11, 249-263.

McCauley, J., Kern, D. E., Kolodner, K., Derogatis, L. R., \& Bass, E. B. (1998). Relation of low-severity violence to women's health. Journal of General Internal Medicine, 13, 687-691.

Pearlin, L. I. (1989). The sociological study of stress. Journal of Health and Social Behavior, 30, 241-256.

Pico-Alfonso, M. A., Garcia-Linares, M. I., Celda-Navarro, N., BlascoRos, C., Echeburua, E., \& Martinez, M. (2006). The impact of physical, psychological, and sexual intimate male partner violence on women's mental health: Depressive symptoms, posttraumatic stress disorder, state anxiety, and suicide. Journal of Women's Health, 15, 599-611.

Price, R. H., Choi, J. N., \& Vinokur, A. D. (2002). Links in the chain of adversity following job loss: How financial strain and loss of personal control lead to depression, impaired functioning, and poor health. Journal of Occupational Health Psychology, 7, 302-312.

Raver, C. C. (2003). Does work pay psychologically as well as economically? The role of employment in predicting depressive symptoms and parenting among low-income families. Child Development, 74, 17201736.

Repetti, R. L., Matthews, K. A., \& Waldron, I. (1989). Employment and women's health. American Psychologist, 44, 1394-1401.

Riger, S., Ahrens, C., \& Blickenstaff, A. (2001). Measuring interference with employment and education reported by women with abusive partners: Preliminary data. Violence and Victims, 15, 161-172.

Riger, S., Ahrens, C., Blickenstaff, A., \& Camacho, J. (1999). Obstacles to employment of women with abuse partners: A summary of select interview data (Working Paper No. GCP-99-1). Chicago: University of Illinois at Chicago, Great Cities Institute.

Riger, S., Staggs, S. L., \& Schewe, P. (2004). Intimate partner violence as an obstacle to employment among mothers affected by welfare reform. Journal of Social Issues, 60, 801-818.

Romero, D., Chavkin, W., Wise, P., \& Smith, L. (2003). Low-income mothers' experience with poor health, hardship, work, and violence: Implications for policy. Violence Against Women, 9, 1231-1244.

Rothman, E. F., Hathaway, J., Stidsen, A., deVries, H. F. (2007). How employment helps female victims of intimate partner violence: A qualitative study. Journal of Occupational Health Psychology, 12, 136-143.

Samuels-Dennis, J. (2006). Relationship among employment status, stressful life events, and depression in single mothers. Canadian Journal of Nursing Research, 38, 58-80.

Sato-DiLorenzo, A., \& Sharps, P. W. (2007). Dangerous intimate partner relationships and women's mental health and health behaviors. Issues in Mental Health Nursing, 28, 837-848.

Shear, M. K., Cloitre, M., Pine, D., \& Ross, J. (2005). Anxiety disorders in women: Setting a research agenda. Silver Springs, MD: Anxiety Disorders Association of American.

Staggs, S. L., \& Riger, S. (2005). Effects of intimate partner violence on low-income women's health and employment. American Journal of Community Psychology, 36, 1-2.

Straus, M. A. (1979). Measuring intrafamily conflict and aggression: The Conflict Tactics Scale (CTS). Journal of Marriage and the Family, 41, 75-88. 
Swanberg, J. E., \& Logan, T. K. (2005). Domestic violence and employment: A qualitative study. Journal of Occupational Health Psychology, 10, 3-17.

Thomas, C., Benzeval, M., \& Stansfeld, S. (2007). Psychological distress after employment transitions: The role of subjective financial position as a mediator. Journal of Epidemiology \& Community Health, 61, 4852.

Tjaden, P., \& Thoennes, N. (2000). Extent, nature, and consequences of intimate partner violence: Findings from the National Violence against Women Survey. Washington, DC: U.S. National Institute of Justice.

Tolman, R. M., \& Raphael, J. (2000). A review of research on welfare and domestic violence. Journal of Social Issues, 56, 655-682.

Tolman, R. M., \& Rosen, D. (2001). Domestic violence in the lives of women receiving welfare: Mental health, substance dependence, and economic well-being. Violence Against Women, 7, 141-158.

Tolman, R. M., \& Wang, H. C. (2005). Domestic violence and women's employment: Fixed effects models of three waves of women's employment study data. American Journal of Community Psychology, 36, 147-158.

Turner, H. A. (2007). The significance of employment for chronic stress and psychological distress among rural single mothers. American Journal of Community Psychology, 40, 181-193.
Von Eye, A., \& Bogat, A. G. (2006). Mental health in women experiencing intimate partner violence as the efficiency goal of social welfare functions. International Journal of Social Welfare, 15, S31-S40.

Wettersten, K. B., Rudolph, S. E., Faul, K., Gallagher, K., Trangsrud, H. B., \& Adams, K. (2004). Freedom through self-sufficiency: A qualitative examination of the impact of domestic violence on the working lives of women in shelter. Journal of Counseling Psychology, 51, 447-462.

Williams, S. L., \& Mickelson, K. D. (2004). The nexus of domestic violence and poverty: Resilience in women's anxiety. Violence Against Women, 10, 283.

Yoshihama, M., Hammock, A. C., \& Horrocks, J. (2006). Intimate partner violence, welfare receipt, and health status of low-income African American women: A lifecourse analysis. American Journal of Community Psychology, 37, 95-109.

Zlotnick, C., Johnson, D. M., \& Kohn, R. (2006). Intimate partner violence and long-term psychosocial functioning in a national sample of American women. Journal of Interpersonal Violence, 21, $262-275$. 